\title{
Robust TIR satellite techniques for monitoring earthquake active regions: limits, main achievements and perspectives
}

\author{
Carolina Aliano $\left({ }^{1}\right)$, Rosita Corrado $\left({ }^{1}\right)$, Carolina Filizzola $\left({ }^{2}\right)$, Nicola Genzano $\left({ }^{1}\right)$, \\ Nicola Pergola $\left({ }^{1}\right)\left({ }^{2}\right)$ and Valerio Tramutoli $\left({ }^{1}\right)\left({ }^{2}\right)$ \\ $\left({ }^{1}\right)$ Dipartimento di Ingegneria e Fisica dell'Ambiente, Università degli Studi della Basilicata, Potenza, Italy \\ $\left.{ }^{2}{ }^{2}\right)$ Istituto di Metodologie per l'Analisi Ambientale (IMAA, CNR), Tito Scalo (PZ), Italy
}

\begin{abstract}
In the last few years, Robust Satellite data analysis Techniques (RST) have been proposed which significantly improved present capabilities to investigate possible relations between TIR signal fluctuations and earthquake occurrence. This paper, starting from a critical survey of results achieved by applying different RST-based algorithms to different satellite sensors to approximately ten earthquakes (two of them are discussed here for the first time) which occurred in three different continents, tries to offer a first assessment of main achievements, residual limits and perspectives of such studies. Even if it is still not possible to relate (or to exclude) observed anomalous TIR transients definitely to impending earthquakes, such studies demonstrate at least: a) the strong improvement of S/N ratio achievable moving from polar to geostationary satellites; $b$ ) the further S/N improvement achievable by using TIR sensors which also offer split-window possibilities; c) the crucial role played by a space-time persistence test to select TIR anomalies candidate to be associated to impending earthquakes; d) the possibility of identifying and correctly discarding TIR anomalies related to clouds and to image navigation errors; e) the scarce importance of spatial resolution of observations which encourages the use of passive MW sensors which are less affected by atmospheric conditions.
\end{abstract}

Key words $R S T$ - Earthquake - satellite thermal infrared - Hector Mine - Izmit - GeoSTAR

\section{Introduction}

The Earth's thermally emitted radiation in the Thermal Infrared $(8-14 \mathrm{~mm})$ spectral range, when measured from sensors on board satellite platforms, is referred to as a TIR signal wich us usually given in units of Brightness Temperature $[\mathrm{K}]$. In the last few decades, a number of

Mailing address: Dr. Carolina Aliano, Dipartimento di Ingegneria e Fisica dell'Ambiente, Università degli Studi della Basilicata, Via dell'Ateneo Lucano, 85100 Potenza, Italy; e-mail:carolaliano@gmail.com papers have been published suggesting the existence of a possible relation between «anomalous» space-time fluctuations (hereafter «thermal anomalies») of such a TIR signal and earthquakes occurrence (e.g. Gorny et al., 1988; Qiang et al., 1991; Qiang and Dian, 1992; Tronin, 1996; Qiang et al., 1997; Salman et al., 1992; Tronin, 2000; Singh et al., 2002; Tronin et al., 2002; Day and Singh, 2003; Ouzounov and Freund, 2004; Cervone et al., 2006; Saraf and Choudhury, 2005a,b).

These papers have been greeted with some scepticism by the scientific community mainly for the poor methods used for the analysis of satellite TIR images (see Tramutoli et al., 2001a) and for the interpretation of results (e.g. Geller, 1997). In fact, the main problems in the above-mentioned studies were the lack of a rig- 
orous definition of anomalous TIR signal fluctuations, the absence of a convincing testing step based on a validation/confutation approach and the scarce attention paid to the possibility that other causes (e.g. meteorological) different from seismic activity could be responsible for the observed TIR variations (Tramutoli et al., 2005).

Within this context, a different approach has been proposed which, unlike preceding methods, permits a statistically based definition of TIR anomaly even in the presence of highly variable contributions from atmospheric (e.g. transmittance), surface (e.g. emissivity and morphology) and observational (time/season, but also solar and satellite zenithal angles) conditions. It was initially proposed for AVHRR-NOAA (Advanced Very High Resolution Radiometer onboard NOAA, National Oceanographic and Atmospheric Administration) data, and therefore it was named «RAT»
(Robust AVHRR Techniques, Tramutoli, 1998), but its full exportability on different satellite systems suggested a more generic name «RST» (Robust Satellite Technique, Tramutoli, 2005), that will be used from now on throughout this paper.

The RST possible applications to satellite TIR surveys in seismically active regions has already been tested in the case of approximately ten earthquakes (see a selection in table I) by using a validation/confutation approach, devoted to verify the presence/absence of anomalous space-time TIR transients in the presence/absence of seismic activity.

This paper discusses the progress and limits of the use of the RST method on seismically active area monitoring by comparing results achieved on different earthquakes which happened in different geographic areas by using different satellite sensors. Progresses in reducing the most important noisy contributions to

Table I. Seismic events which have been studied by applying the RST approach: the used variable V(r,t), the sensor, the length (years) and homogeneity rules (months of the year, time of the day) which have been applied to build the historical data-set (used to compute reference images $\mu_{\mathrm{V}}$ and $\sigma_{\mathrm{V}}$ ) and the minimum $\mathrm{S} / \mathrm{N}$ ratio of TIR anomalies are indicated, together with the references.

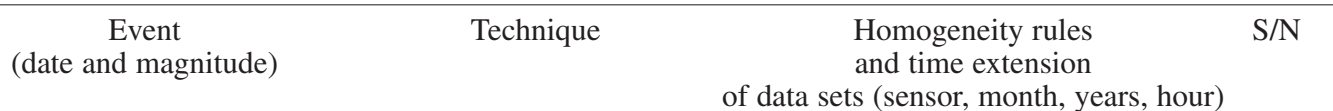

Polar satellites

23 November 1980,

Irpinia-Basilicata-Italy $M s=6.9$

23 November 1980, Irpinia-Basilicata, Italy $M s=6.9$

7 September 1999

Athens, Greece $M s=5.9$
$<\otimes_{\Delta T}(r)>-$ monthly average

(Tramutoli et al., 2001a)

$<\otimes_{L S T}(r)>-$ monthly average

(Di Bello et al., 2004)

$\otimes_{L S T}(r, t)$ - daily analysis

(Filizzola et al., 2004)
AVHRR - November

(1994-1998) -17:00 -19:00

0.6

AVHRR - November

(1994-1998) -17:00 -19:00

AVHRR - August and September

(1995-1998) - 1:00-4:00 GMT

Geostationary satellites

17 August 1999,

Kocaeli-Izmit, Turkey $M s=7,8$

26 September 1997 , Umbria, Italy

$M s=5.9$ to 6.4

$$
\begin{gathered}
\otimes T(r, t)-\text { daily analysis } \\
\text { (this paper) } \\
\otimes_{\Delta T}(r, t)-\text { daily analysis } \\
\quad(\text { Aliano, 2004) }
\end{gathered}
$$

METEOSAT - August

(1995-2000) -24:00GMT

METEOSAT - September

(1992-2000) - 24:00 GMT 
Table I (continued).

\begin{tabular}{|c|c|c|c|}
\hline $\begin{array}{c}\text { Event } \\
\text { (date and magnitude) }\end{array}$ & Technique & $\begin{array}{c}\text { Homogeneity rules } \\
\text { and time extension } \\
\text { of data sets (sensor, month, years, hour) }\end{array}$ & $\mathrm{S} / \mathrm{N}$ \\
\hline $\begin{array}{l}\text { 3-7-12-14 October } 1997, \\
\text { Umbria, Italy } \\
M s=5.7 \text { max }\end{array}$ & $\begin{array}{c}\otimes_{\Delta T}(r, t)-\text { daily analysis } \\
\quad \text { (Abbate, 2005) }\end{array}$ & $\begin{array}{l}\text { METEOSAT -October } \\
(1992-2000)-24: 00 \text { GMT }\end{array}$ & 2.5 \\
\hline $\begin{array}{c}16 \text { October 1999, } \\
\text { Hector Mine, California } \\
\qquad s=7,4\end{array}$ & $\begin{array}{c}\otimes_{\Delta T}(r, t) \text { - daily analysis } \\
\text { (this paper) }\end{array}$ & $\begin{array}{c}\text { GOES - October } \\
\text { (1996-1999)- 24:00 GMT }\end{array}$ & 2.5 \\
\hline $\begin{array}{l}7 \text { September } 1999 \\
\text { Athens, Greece } \\
M s=5.9\end{array}$ & $\begin{array}{l}\otimes_{\Delta T}(r, t) \text { - daily analysis } \\
\text { (Filizzola et al., 2004) }\end{array}$ & $\begin{array}{l}\text { METEOSAT - August \&September } \\
(1995-1998) \text { 24:00 GMT }\end{array}$ & 3 \\
\hline $\begin{array}{c}21 \text { May } 2003 \\
\text { Zemmouri, Algeria } \\
M s=6.9\end{array}$ & $\begin{array}{l}\otimes_{\Delta T}(r, t)-\text { daily analysis } \\
\quad \text { (Aliano et al., 2006) }\end{array}$ & $\begin{array}{l}\text { METEOSAT - April and May } \\
(1992-1999) \text { - 24:00 GMT }\end{array}$ & 3 \\
\hline $\begin{array}{l}28 \text { May } 1995, \\
\text { Patras, Greece } \\
\quad M b 4.7\end{array}$ & $\begin{array}{l}\otimes_{\Delta T}(r, t)-\text { daily analysis } \\
\quad(\text { Corrado et al., 2005) }\end{array}$ & $\begin{array}{c}\text { METEOSAT - May } \\
(1992-1999)-24: 00 \text { GMT }\end{array}$ & 3 \\
\hline $\begin{array}{l}29 \text { May } 1995, \\
\text { Cyprus } \\
M b 5.3\end{array}$ & $\begin{array}{l}\otimes_{\Delta T}(r, t)-\text { daily analysis } \\
\text { (Corrado et al., 2005) }\end{array}$ & $\begin{array}{c}\text { METEOSAT - May } \\
(1992-1999)-24: 00 \text { GMT }\end{array}$ & 3 \\
\hline $\begin{array}{l}3 \text { June } 1995 \\
\text { Crete, Greece } \\
\text { Mb } 4.2\end{array}$ & $\begin{array}{l}\otimes_{\Delta T}(r, t)-\text { daily analysis } \\
\quad(\text { Corrado et al., 2005) }\end{array}$ & $\begin{array}{l}\text { METEOSAT - June } \\
\text { 1992-1999) - 24:00 GMT }\end{array}$ & 3 \\
\hline $\begin{array}{l}18 \text { June } 1995, \\
\text { Crete, Greece } \\
\quad M b 4.9\end{array}$ & $\begin{array}{l}\otimes_{\Delta T}(r, t)-\text { daily analysis } \\
\quad(\text { Corrado } \text { et al., 2005) }\end{array}$ & $\begin{array}{c}\text { METEOSAT - June } \\
(1992-1999)-24: 00 \text { GMT }\end{array}$ & 3 \\
\hline $\begin{array}{l}4 \text { May } 1996, \\
\text { Erzurum,Turkey } \\
\text { Mb } 4.2\end{array}$ & $\begin{array}{l}\otimes_{\Delta T}(r, t)-\text { daily analysis } \\
\quad(\text { Corrado } \text { et al., 2005) }\end{array}$ & $\begin{array}{c}\text { METEOSAT - May } \\
\text { (1992-1999) - 24:00 GMT }\end{array}$ & 3 \\
\hline $\begin{array}{c}13 \text { June } 1996, \\
\text { Ionian Sea } \\
\text { (Southern Greece) } \\
M b 4.2\end{array}$ & $\begin{array}{l}\otimes_{\Delta T}(r, t)-\text { daily analysis } \\
\quad(\text { Corrado et al., 2005) }\end{array}$ & $\begin{array}{c}\text { METEOSAT - June } \\
(1992-1999)-24: 00 \text { GMT }\end{array}$ & 3 \\
\hline $\begin{array}{l}16 \text { June } 1996, \\
\text { Patras, Greece, } \\
\quad M b 4.3\end{array}$ & $\begin{array}{l}\otimes_{\Delta T}(r, t)-\text { daily analysis } \\
\quad(\text { Corrado et al., 2005) }\end{array}$ & $\begin{array}{c}\text { METEOSAT - June } \\
(1992-1999)-24: 00 \text { GMT }\end{array}$ & 3 \\
\hline $\begin{array}{l}17 \text { June 1996, } \\
\text { Crete, Greece } \\
\text { Mb } 4.0\end{array}$ & $\begin{array}{l}\otimes_{\Delta T}(r, t)-\text { daily analysis } \\
\quad(\text { Corrado } \text { et al., 2005) }\end{array}$ & $\begin{array}{c}\text { METEOSAT June } \\
(1992-1999)-24: 00 \text { GMT }\end{array}$ & 3 \\
\hline $\begin{array}{l}29 \text { June } 1996, \\
\text { Isparta, Turkey } \\
\text { Mb } 5.1\end{array}$ & $\begin{array}{l}\otimes_{\Delta T}(r, t)-\text { daily analysis } \\
\text { (Corrado et al., 2005) }\end{array}$ & $\begin{array}{c}\text { METEOSAT - June } \\
(1992-1999)-24: 00 \text { GMT }\end{array}$ & 3 \\
\hline $\begin{array}{c}26 \text { January } 2001 \\
\text { Gujarat, India } \\
M s=7.9\end{array}$ & $\begin{array}{l}\otimes_{\Delta T}(r, t)-\text { daily analysis } \\
(\text { Genzano et al., 2007) }\end{array}$ & $\begin{array}{l}\text { METEOSAT - January \&February } \\
\quad(1999-2004) \text { - 24:00 GMT }\end{array}$ & 3 \\
\hline $\begin{array}{c}17 \text { August 1999, } \\
\text { Kocaeli-Izmit, Turkey } \\
M s=7,8\end{array}$ & $\begin{array}{l}\otimes \mathrm{T}(\mathrm{r}, \mathrm{t}) \text { - daily analysis } \\
(\text { Tramutoli et al., 2005) }\end{array}$ & $\begin{array}{c}\text { METEOSAT August } \\
(1992-1998,2000)-24: 00 \text { GMT }\end{array}$ & 3.5 \\
\hline
\end{tabular}


the measured signal will be discussed by considering new explanatory cases.

\section{A robust satellite-based TIR index}

A wider description of the RST approach and its implementation on different satellite sensors to monitor seismic areas can be found in different papers (Tramutoli et al., 2001a; Di Bello et al., 2004; Filizzola et al., 2004; Corrado et al., 2005; Tramutoli et al., 2005; Aliano et al., 2007; Genzano et al., 2007).

The above mentioned papers used specific indexes, such as the RETIRA (Robust Estimator of TIR Anomalies, after Tramutoli et al., 2005) which belongs to a more general class of ALICE (Absolutely Llocal Index of Change of the Environment) indexes which give a statistically well based definition of llocal signal anomalies (since Tramutoli, 1998 the double $l$ is used to make reference not only to a specific place $\boldsymbol{r}^{\prime}$ but also to a specific time $t^{\prime}$ ).

Using a general formula, ALICE indexes are computed on the image at hand as follows:

$$
\otimes_{V}(\boldsymbol{r}, t)=\frac{V(\boldsymbol{r}, t)-\mu_{V}(\boldsymbol{r})}{\sigma_{V}(\boldsymbol{r})}
$$

where $\boldsymbol{r} \equiv(x, y)$ represents location coordinates on a satellite image; $t$ is the time of image acquisition with $t \in \tau$, where $t$ defines the homogeneous domain of satellite imagery collected during the years in the same time-slot of the day and period (e.g. same month) of the year; $V(\boldsymbol{r}, t)$ is the value of a variable $V$ at location $\boldsymbol{r} \equiv(x, y)$ and at acquisition time $t ; \mu_{V}(\boldsymbol{r})$ is the time average value of $V(\boldsymbol{r}, t)$ at location $\boldsymbol{r} \equiv(x, y)$ computed on cloud free records belonging to the selected data set $(t \in \tau)$; $\sigma_{V}(\boldsymbol{r})$ is the standard deviation of $V(\boldsymbol{r}, t)$ at the location $r \equiv(\mathrm{x}, \mathrm{y})$ computed on cloud free records belonging to the selected data set $(t \in \tau)$.

The choice of the variable $V(\boldsymbol{r}, t)$ depends on the specific application and on particular effects that we want to take into account. RST has been indeed successfully applied to the major natural and environmental hazards related to: volcano activity (Pergola et al., 2001; Tramutoli et al., 2001b; Di Bello et al., 2004; Pergola et al., 2004a,b; Bonfiglio et al., 2005; Marchese et al. 2006; Filizzola et al. 2007); flood risk (Tramu- toli et al., 2001c; Lacava et al., 2005; Lacava et al 2006); forest fires (Cuomo et al., 2001), etc.

For its application to seismic area monitoring, different variables have been used

$$
V(\boldsymbol{r}, t) \equiv\left\{\begin{array}{l}
T(\boldsymbol{r}, t) \\
\Delta T(\boldsymbol{r}, t) \equiv T(\boldsymbol{r}, t)-T(t) \\
\left(\text { the corresponding } \otimes_{\Delta T}(\boldsymbol{r}, t)\right. \\
\text { index is also named RETIRA }) \\
\Delta \operatorname{LST}(\boldsymbol{r}, t) \equiv \operatorname{LST}(\boldsymbol{r}, t)-\operatorname{LST}(t)
\end{array}\right.
$$

where $T(\boldsymbol{r}, t)$ is simply the TIR radiance at the sensor; LST (Land Surface Temperature) is a product of satellite data analysis, which is expected to give, starting from observations in two spectrally very close TIR bands (split-windows), an estimate of the Earth's Surface Temperature corrected for the effects of atmospheric water vapour content (see Di Bello et al. 2004 and reference herein); $T(t)$ and $\operatorname{LST}(t)$ are spatial averages of $T(\boldsymbol{r}, t)$ and $\operatorname{LST}(\boldsymbol{r}, t)$ computed in place on the image at hand considering cloud-free pixels only, separately for land and sea: only sea pixels are used to compute $\Delta T(\mathbf{r}, t)$ and $\Delta \operatorname{LST}(\mathbf{r}, t)$ if $\boldsymbol{r}$ is located on the sea; only land pixels are used on the other hand if $\boldsymbol{r}$ is located on land. The use of the excesses $\Delta \mathrm{T}(\boldsymbol{r}, t)$ and $\Delta \mathrm{LST}(\boldsymbol{r}, t)$, instead of the simple $T(\boldsymbol{r}, t)$ and $\operatorname{LST}(\boldsymbol{r}, t)$, is expected to reduce the possible contributions (e.g. occasional warming) to the signal due to the year-to-year climatic changes and/or season time-drifts which usually affect near-surface temperature at a regional scale (Tramutoli et al., 2005).

By construction, the ALICE indexes turn out to be useful tools for a robust identification of TIR anomalies and allow us to estimate them in terms of Signal-to-Noise $(\mathrm{S} / \mathrm{N})$ ratio. In fact, the local excess $V(\boldsymbol{r}, t)-\mu_{V}(\boldsymbol{r})$, which represents the Signal (S) to be investigated for its possible relation with seismic activity, is evaluated by comparison with the corresponding observational/natural Noise $(\mathrm{N})$ represented by $\sigma_{V}(\boldsymbol{r})$. It is important to note that $\sigma_{V}(\boldsymbol{r})$ includes all (natural and observational, known and unknown) sources of the overall (llocal) variability of $S$ as historically observed at the same site in similar observational conditions (same platform, time of day, month, etc). This way, the relative im- 
portance of the measured TIR signal (or the intensity of anomalous TIR transients) can naturally be evaluated in terms of $\mathrm{S} / \mathrm{N}$ ratio by the ALICE indexes.

As a result, ALICE indexes are intrinsically resistant to false alarms and, in addition, may assure a complete exportability to different geographical areas and a free choice of sensors to be used.

\section{Possible choices for the TIR-based variable $V(r, t)$ : results for different satellite sensors}

As indicated in the previous section, different choices, described in (2.2), are possible for the variable $V(\boldsymbol{r}, t)$ in the general expression $(2.1)$.

The first application of the RST approach to seismically active areas was performed using polar satellite data (NOAA-AVHRR) and RETIRA index on the Irpinia-Basilicata (23 November 1980, $M_{s}=6.9$ ) earthquake (Tramutoli et al., 2001a). In that case, the monthly average $<\otimes_{\Delta T}(\boldsymbol{r})>$ of the $\otimes_{\Delta T}(\boldsymbol{r}, t)$ index was considered to compare the mean signal observed during the month of the earthquake (November 1980) with the one observed during the same month in different years.

These preliminary studies showed how the RST approach is able to strongly reduce site effects (e.g. related to horography, land cover, etc). In addition, validation results showed more anomalous pixels than in «unperturbed» years (confutation) and in a better correlation with spatial distribution of seismogenic areas (as in Valensise et al., 1993). However the monthly average $<\otimes_{\Delta T}(\boldsymbol{r})>$ of the $\otimes_{\Delta T}(\boldsymbol{r}, t)$ index rarely reached values greater than 0.6 . A significant improvement of $\mathrm{S} / \mathrm{N}$ ratio (see also fig. 1) was achieved by using the monthly averages $<\otimes_{\Delta \mathrm{LST}}(\boldsymbol{r})>$ of the $\otimes_{\Delta \mathrm{LST}}(\boldsymbol{r}, t)$ index, instead of $\left\langle\otimes_{\Delta T}(\boldsymbol{r})\right\rangle$ (pictures on the right in fig. 2). In fact, as $\operatorname{LST}(\boldsymbol{r}, t)$ gives an estimate of the land surface temperature corrected by the effects of atmospheric water vapour content, it is expected that $\sigma_{\Delta \mathrm{LST}}(\boldsymbol{r}, t)<\sigma_{\Delta T}(\boldsymbol{r}, t)$ with a consequent increase in $\mathrm{S} / \mathrm{N}$ ratio. In the case of the IrpiniaBasilicata earthquake, computing LST values with Becker and Li (1990) algorithm, an increase in $\mathrm{S} / \mathrm{N}$ ratio from 0.6 to 1 was achieved (Di Bello et al., 2004).

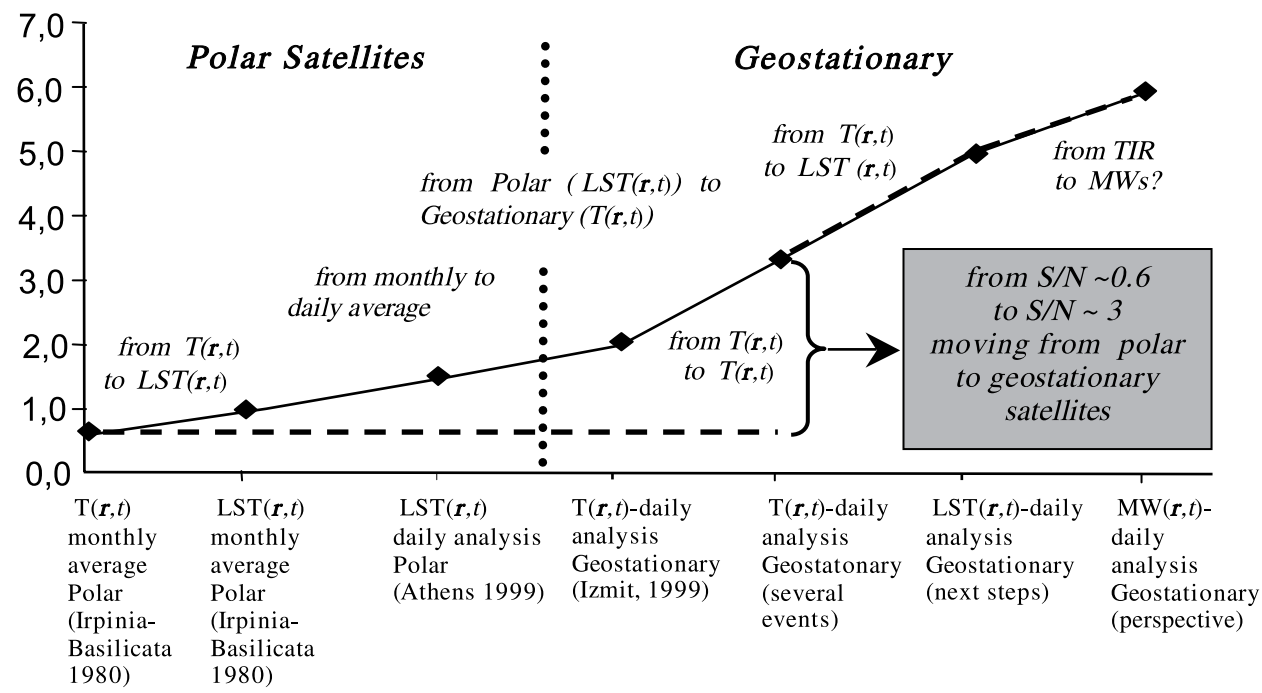

Fig. 1. S/N evolution after the application of the RST approach to different satellite sensors and different ALICE indexes. 

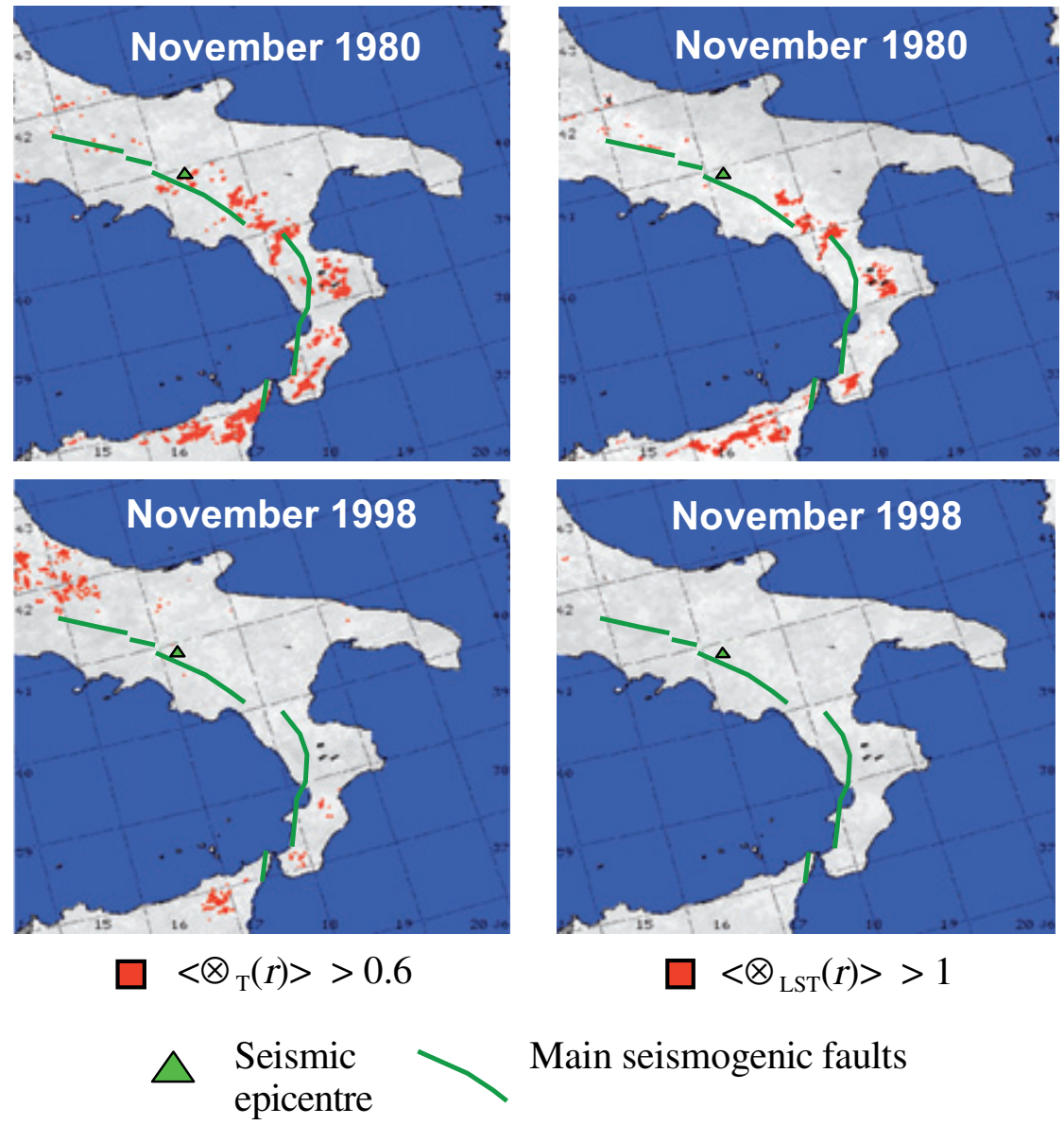

Main seismogenic faults

Fig. 2. The RST approach applied to polar satellite data (NOAA-AVHRR). Comparison between the results of the analysis on monthly average $<\otimes_{\Delta T}(\boldsymbol{r})>$ of $\otimes_{\Delta T}(\boldsymbol{r}, t)(l e f t)$ and $<\otimes_{\Delta L S T}(\boldsymbol{r})>$ of $\otimes_{\Delta L S T}(\boldsymbol{r}, t)($ right $)$ indexes, computed for (top) November 1980 (year of Irpinia's earthquake) and (bottom) November 1998, one of seismically unperturbed (i.e. no earthquakes with $M>4$ in the study area) years (adapted from Tramutoli et al., 2001a; Di Bello et al., 2004). The unperturbed signal behaviour, in terms of $\mu_{\Delta \mathrm{T}}(\boldsymbol{r})$ and $\sigma_{\Delta \mathrm{T}}(\boldsymbol{r})$ or $\mu_{\Delta \mathrm{LST}}(\boldsymbol{r})$ and $\sigma_{\Delta L S T}(\boldsymbol{r})$, was determined on the basis of five years of NOAA-AVHRR records collected in similar observational conditions (see table I).

Figure 2 clearly shows this improvement: for November 1980 (validation) the spatial distribution of pixels with $\otimes_{\Delta T}(\boldsymbol{r}, t)>0.6$ and $\otimes_{\Delta \mathrm{LST}}(\boldsymbol{r}, t)>1$ is rather similar, but, for the unperturbed November 1998 period (confutation), pixels with $\left\langle\otimes_{\Delta \mathrm{LST}}(\boldsymbol{r})\right\rangle>1$ almost disappear, differently from pixels with $\left\langle\otimes_{\Delta T}(\boldsymbol{r})\right\rangle>0.6$. Moreover, in both cases thermal anomalies seem to occur even far away (up to several hundred kilometres) from the epicentre zone.

A subsequent study (Filizzola et al., 2004) on AVHRR data demonstrated that a significant increase in $\mathrm{S} / \mathrm{N}$ ratio is achievable moving from monthly $\left(<\otimes_{\Delta \mathrm{LST}}(\boldsymbol{r})>\right)$ to daily $\left(\otimes_{\Delta \mathrm{LST}}(\boldsymbol{r}, t)\right)$ indexes. In this case $\otimes_{\Delta \mathrm{LST}}(\boldsymbol{r}, t)$ values greater than 1.5 were observed to draw anomalous space- 


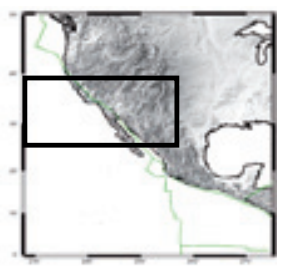

Clouds

$\triangle$ Seismic epicentre

Main tectonic lineaments

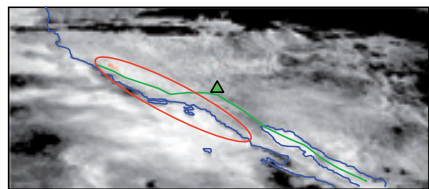

1 October 1999

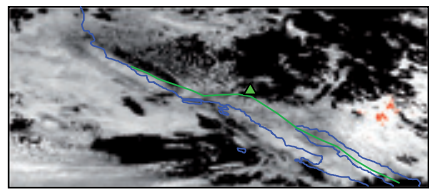

7 October 1999

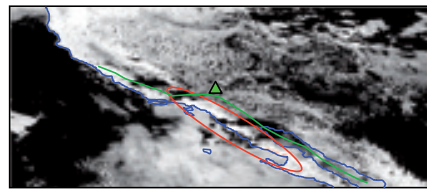

21 October 1999

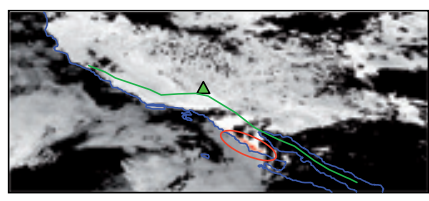

25 October 1999

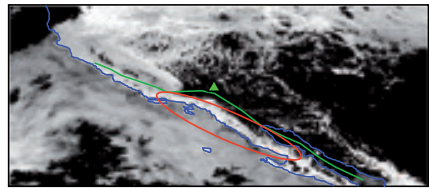

31 October 1999

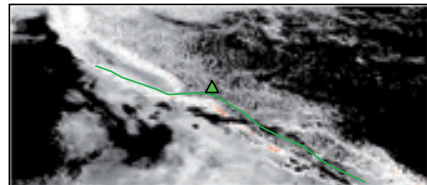

20 October 1999

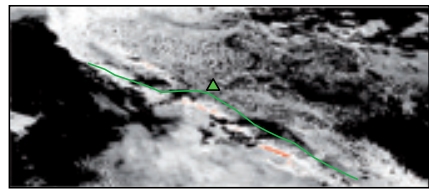

21 October 1999

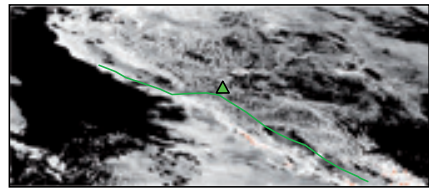

22 October 1999

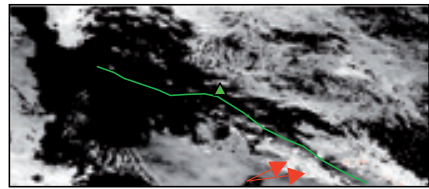

23 October 1999

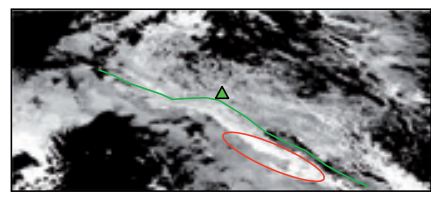

24 October 1999

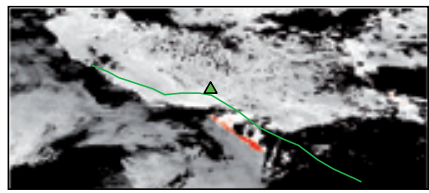

25 October 1999

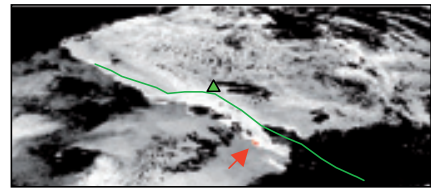

26 October 1999

$\square \otimes_{\mathrm{T}}(r, t)>2$

Fig. 3. The RST approach applied to geostationary satellite data (GOES). Results of the analysis of the daily $\otimes_{\Delta T}(r, t)$ index on the epicentral area before and after earthquake $\left(M_{s}=7.4\right)$ of Hector Mine (California) occurred on October 16th 1999. Left side: results of the analysis performed on GOES images collected from October 1st to 31st with pixels having $\otimes_{\Delta T}(r, t)>2.5$ depicted in red. Right side: results of the analysis performed from October 16th to 26th with pixels having $\otimes_{\Delta T}(r, t)>2$ depicted in red. Note that, images corresponding to mostly overcast days or without any thermal anomaly on the scene are not shown in the figure (see text). 
time TIR patterns affecting the epicentre area a few days before the Athens $\left(M_{S}=5.9\right)$ earthquake which occurred on September 7th, 1999. The use, for the first time, of daily $\otimes_{\Delta \mathrm{LST}}(\boldsymbol{r}, t)$ observations demonstrated the importance of a temporal and spatial persistence analysis of TIR anomalies in order to discriminate meaningful anomalous transients from signal outliers with similarly high $\mathrm{S} / \mathrm{N}$ values (see also Tramutoli et al., 2005; Genzano et al., 2007).

In the same study, Filizzola et al. (2004) compared results they achieved by using $V(\boldsymbol{r}, t)=\Delta \mathrm{LST}(\boldsymbol{r}, t)$ on AVHRR data with the ones achieved by using on the contrary $\mathrm{V}(\boldsymbol{r}, t)=\Delta T(\boldsymbol{r}, t)$ on Meteosat observations. Due to the absence of split-windows TIR bands on Meteosat, it was impossible to use the same RETIRA index for both, the polar AVHRR and the geostationary Meteosat, satellites.

However, this circumstance allowed the authors to make a first analysis of the trade-off between the best choice of $V(\boldsymbol{r}, t)$ in (2.1), which is also related to satellite sensor spectral capabilities, and satellite attitude itself. In fact, compared with polar satellites, geostationary satellites guarantee for each ground location, even if at lower spatial resolution, constant view angles with the same ground resolution cell size and precise image-to-image co-location. Time-slots which are no longer than 30 min guarantee higher homogeneity of imagery time series further reducing the contribution to the signal variability simply due to image-to-image changes in observational time. For this reason, achievable $\mathrm{S} / \mathrm{N}$ is expected to improve, as a consequence of reduction of $\sigma_{V}(\boldsymbol{r}, t)$, not only moving from $\mathrm{V}(\boldsymbol{r}, t)=\Delta T(\boldsymbol{r}, t)$ to $\mathrm{V}(\boldsymbol{r}, t)=\Delta \mathrm{LST}(\boldsymbol{r}, t)$, but also moving from polar to geostationary satellite attitudes. In the case of the Athens September 7th 1999 earthquake, it was demonstrated that geostationary attitude, more than the availability of TIR split-window sensors on board polar satellites, allows us to have a major reduction of observational noise with the possibility of reaching a higher $\mathrm{S} / \mathrm{N}$ levels (see fig. 1).

The same good performances on geostationary data (Meteosat, in this case) were observed by Corrado et al. (2005) in the case of mediumlow magnitude events which occurred in Greece and Turkey (see table I). Also in that case, thermal anomalies were observed in known tectonic lineaments even if the most spectacular case of such a correspondence remains the case of Gujarat's earthquake (January 26th, 2001, Ms=7.9), where the whole IndiaEurasia boundary plate seems to be drawn by TIR anomalies (Genzano et al., 2007). The indication for possible large scale effects confirms, also in this case, that high spatial resolution is not a requirement for this kind of study.

\subsection{Two notable study cases: Hector Mine and Izmit-Kocaeli, 1999 earthquakes}

Potentialities and limits of the RST approach have been assessed starting from a critical analysis of results achieved by applying: a) different ALICE indexes to b) different satellite sensors in c) different geographic areas affected by d) different kinds of earthquakes.

In this paper, the RST approach has been applied to two new test-cases (see table I and fig. 1):

1) The seismic event of $M_{s}=7.4$ which occurred on October 16th, 1999 in California, along the San Andreas Fault with the epicentre located near Hector Mine. In this case, RST performances were evaluated, for the first time, on GOES (Geostationary Operational Environment Satellites operated by NOAA) satellite TIR data and on the American continent.

2) The Kocaeli-Izmit earthquake of $M_{s}=7.8$ which struck Turkey, along the North Anatolian Fault (NAF), on August 17th 1999. In this case, RST performances were evaluated, for the first time, by applying the ALICE index based on the choice $V(\boldsymbol{r}, t)=T(\boldsymbol{r}, t)$ to Meteosat TIR observations.

It should be mentioned that important analogies exist between the San Andreas Fault system in California (e.g. USGS, 2000) and the NAF Zone (NAFZ) in Turkey. It is similar is the apprehension for the possible impact of a large magnitude earthquake in such densely populated areas.

It is also notable that both the above mentioned fault systems give a unique opportunity of studying to which extent seismic stress transfer alters the probability of subsequent earthquakes, and for this reason they are among the most studied tectonic areas around the world. 


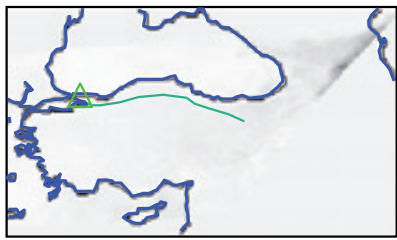

6 August 1999

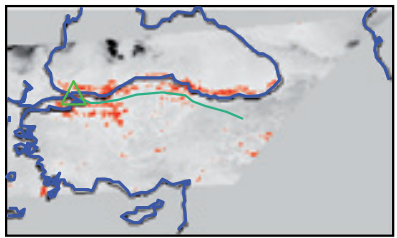

13 August 1999

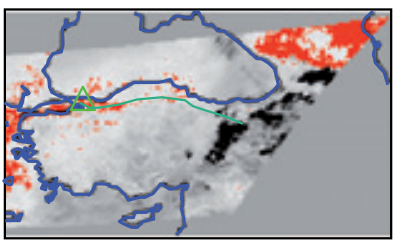

17 August 1999

(Izmit earthquake)

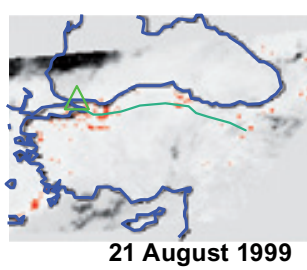

a)

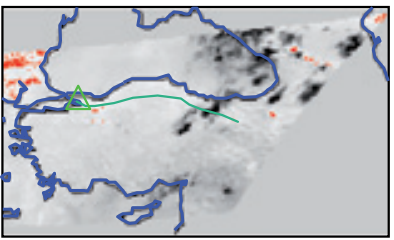

11 August 1999

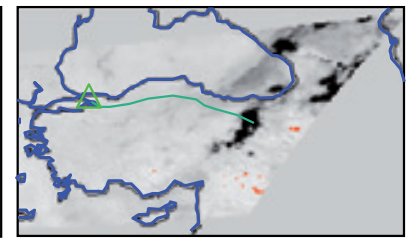

15 August 1999

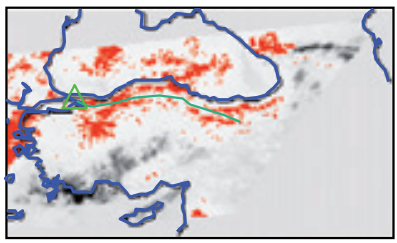

19 August 1999
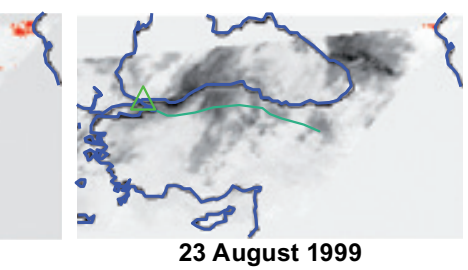

23 August 1999

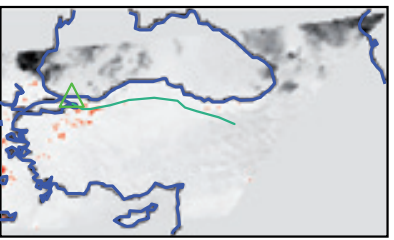

12 August 1999

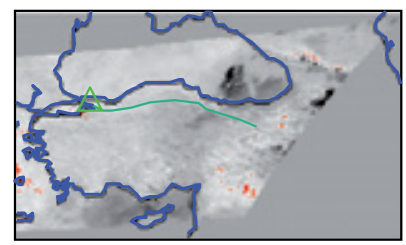

16 August 1999

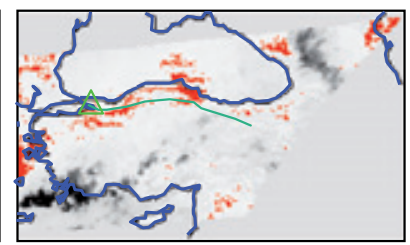

20 August 1999

$\otimes_{\mathrm{T}}(r, t)>2$

口 Clouds

$\triangle \begin{aligned} & \text { Seismic } \\ & \text { epicentre }\end{aligned}$

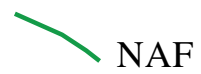

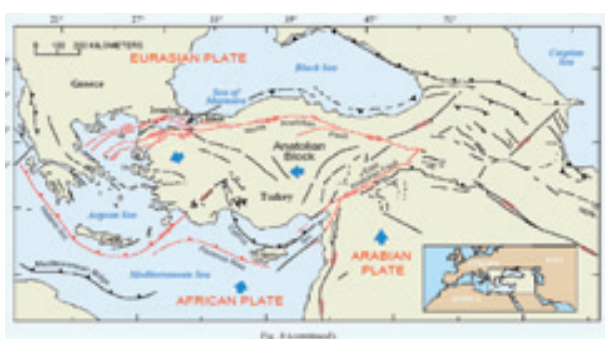

b)

Fig. 4a,b. a) The RST approach applied to geostationary satellite data (Meteosat). Results of the analysis of the daily $\otimes_{T}(r, t)$ index computation on the epicentral area before and after the August 17th 1999 Izmit earthquake; b) tectonic map of the region including the North Anatolian Fault (modified from Barka, 1992). 
In the case of the Hector Mine event, the analysis was carried out by using GOES-9 and GOES-10 I-M Imager data. Four years of satellite observations, from 1996 to 1999, were used for computing $\sigma_{\Delta T}(\boldsymbol{r}, t)$ and $\mu_{\Delta T}(\boldsymbol{r}, t)$ reference fields. Figure 3 (left side) shows that few, but well localized, pixels with $\otimes_{\Delta T}(\boldsymbol{r}, t)>2.5$ appear a few weeks before and a few days after the seismic event. Except on October 7th, all anomalous transients are located in a space around the seismic epicentre and arrange themselves in lineaments which seem to run parallel to tectonic structures, among which there is the San Andreas Fault, responsible for the earthquake. This circumstance appears evidently not casual after the inspection of fig. 3 (right-side) showing the distribution of TIR anomalies, of lower $\left(\otimes_{\Delta T}(\boldsymbol{r}, t)>2\right)$ relative intensity, which occurred after the earthquake (from October 16th until October 26th). Their particular shape and alignment with the San Andreas fault system, together with their space-time persistence, allow us to attribute a particular significance also to the isolated, anomalous transients observed before the earthquake on October 1st and October 7th (see fig. 3, left side). In fact, October 7th anomalies actually appear isolated in space-time while some spatial persistence, in relation to the previous mentioned TIR anomalies sequence, is quite evident in the case of October 1st anomalies.

Therefore, in spite of the scarcity of anomalous pixels, a certain space-time correlation between TIR anomalies and the considered seismic event cannot be excluded.

The spatial correlation between TIR anomalies and tectonic structures was highlighted, even by using $\otimes_{T}(\boldsymbol{r}, t)$, the simplest of the ALICE indexes, instead of a more robust $\otimes_{\Delta T}(\boldsymbol{r}, t)$ RETIRA index, as demonstrated in the test case of Izmit earthquake, which has been studied using both indexes on the same Meteosat-7 geostationary data (fig. 4). Notwithstanding the same spurious effects on the Caucasus region due to a seasonal warming over the area, which can be reduced by using the $\otimes_{\Delta T}(\boldsymbol{r}, t)$ index, as demonstrated in Tramutoli et al. (2005), some thermal anomalies with an intensity of $\otimes_{T}(\boldsymbol{r}, t)>2$ clearly show a trend which seems to gather along the NAF a few days before the occurrence of the earthquake. It should also be noted that the increase in TIR anomaly spatial distribution along the whole NAFZ until August 13th (i.e. 4 days before the earthquake) the decrease of TIR anomalies until the day of the seismic event, the new increase in TIR anomalies in the post seismic period, describe a spatial-temporal dynamics which is in good agreement with the model proposed in Scholz et al. (1973) to explain different phenomena possibly associated to earthquake preparation phases.

It should be highlighted that, even in comparison with the best results $(\mathrm{S} / \mathrm{N} \sim 1.5)$ previously achieved on polar satellite sensors using the most refined variable $V(\boldsymbol{r}, t)=\Delta \mathrm{LST}(\boldsymbol{r}, t)$, the application of the RST approach to geostationary data leads to better $(\mathrm{S} / \mathrm{N} \sim 2)$ results already with the simplest $V(r, t)$ choice. This confirms the main role played by the stability of observational conditions associated with the geostationary attitude in improving RST performances with respect to sensor spectral capabilities and, also in addition, to the choice of the $V(\boldsymbol{r}, t)$ variable in (2.1). On the other hand, the comparison with results achieved by using a more robust index $\otimes_{\Delta T}(\boldsymbol{r}, t)$ (see Tramutoli et al. 2005, for details), straddling the day of Izmit earthquake (see fig. 5), clearly shows the effectiveness of the RETIRA index not only in reducing spurious effects related to occasional warming at a regional scale, but also in improving $\mathrm{S} / \mathrm{N}$ ratio up to the highest levels $\left(\otimes_{\Delta T}(\boldsymbol{r}, t)>3,5\right)$. At this stage and on the basis of the tests performed up to now on several earthquakes which occurred in 3 different continents, the combination of TIR sensors on board geostationary satellites and the choice $V(\boldsymbol{r}, t)=\Delta T(\boldsymbol{r}, t)$ demonstrated to guarantee the best RST performances.

\section{Present limits and perspectives}

Seismic area monitoring by TIR satellite surveys finds an intrinsic limitation when many of cloudy pixels dominate the scene. In fact, cloud cover always prevents Earth's emitted TIR signal from reaching the satellite sensor so that surface or low atmospheric phenomena are not detectable if clouds are present. Moreover, if the cloudiness is very wide and persistent, the scene can be so «obscured» that it is difficult to appreciate space-time continuity of observed TIR anomalies which, as in the case of Hector- 


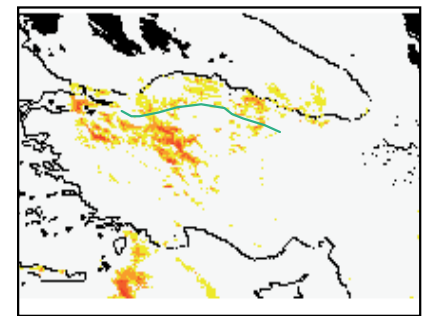

13 August 1999

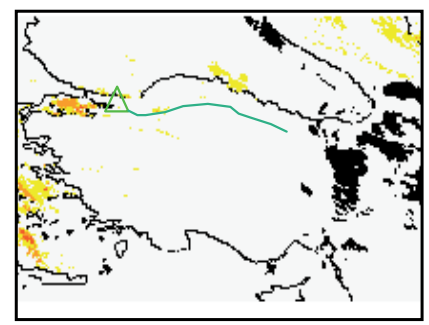

17 August 1999

(Izmit earthquake)

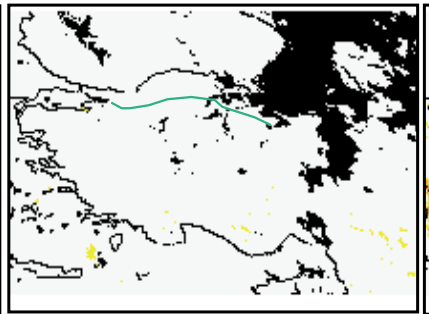

15 August 1999

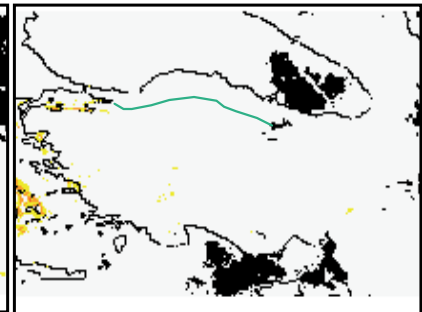

16 August 1999

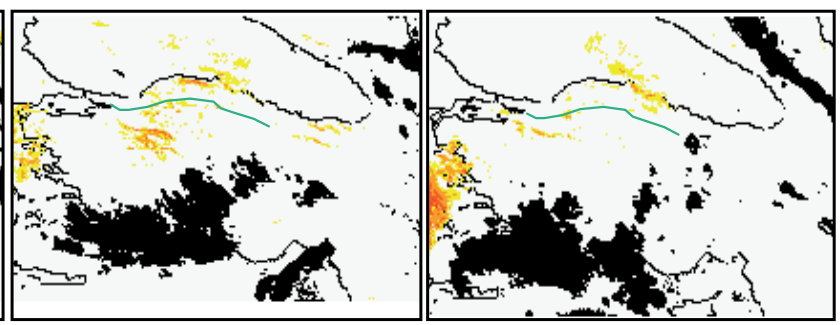

19 August 1999

20 August 1999
$\otimes_{\mathrm{T}}(r, t)>2$
Clouds

$$
\otimes_{\mathrm{T}}(r, t)>2.5
$$

$\otimes_{\mathrm{T}}(r, t)>3.5$
Seismic epicentre

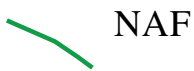

Fig. 5. The RST approach applied to geostationary satellite data (Meteosat). Results of the analysis of the daily $\otimes_{\Delta T}(r, t)$ index computation on the epicentral area of the day of Izmit's earthquake. The unperturbed signal behaviour, in terms of $\mu_{\Delta T}(r)$ and $\sigma_{\Delta T}(r)$, was determined on the basis of eight years of satellite records collected in similar observational conditions (adapted from Tramutoli et al., 2005).

Mine earthquake previously discussed, can be crucial in order to assess the actual significance of observed anomalous signal transients.

The opacity of clouds to TIR radiation introduces further problems when ALICE indexes, and particularly RETIRA ones, are used. Actually, the temporal persistence of clouds over the same area, determining data missing in the observational TIR data-set, may influence multi-temporal analysis.

In our case, the reduction in the population of satellite TIR time-serie records usable to build historical reference fields may locally affect the computed values of ALICE indexes in (2.2). In addition, the geographic distribution of clouds over a thermally heterogeneous scene turns out to heavily affect the computation of the spatial averages $T(t)$ and $\operatorname{LST}(t)$ used to compute $\Delta T(\boldsymbol{r}, t)$ and $\Delta \mathrm{LST}(\boldsymbol{r}, t)$ values in the expression of RETIRA indexes in (2.2). In fact, as emerged from our analysis on hundreds of satellite images, if clouds gather mainly over the warmest portions of a scene. $T(t)$ spatial averages will result lower than the expected clear sky values. This eventuality may cause false $\Delta T(\boldsymbol{r}, t)$ anomalies which spread over almost all clear portions of the scene. This is due to spurious excesses $\Delta T(\boldsymbol{r}, t)=T(\boldsymbol{r}, t)-T(t)$, as a result of the underestimation of $T(t)$ because of the exclusion, due to the presence of clouds, of the warmest fraction of the scene which normally contribute to increase $T(t)$ value. The particular spatial distribution of this kind of TIR anomalies normally allows us to easily identify them and, in any case, to distinguish them from the spatially and temporally persistent ones possi- 

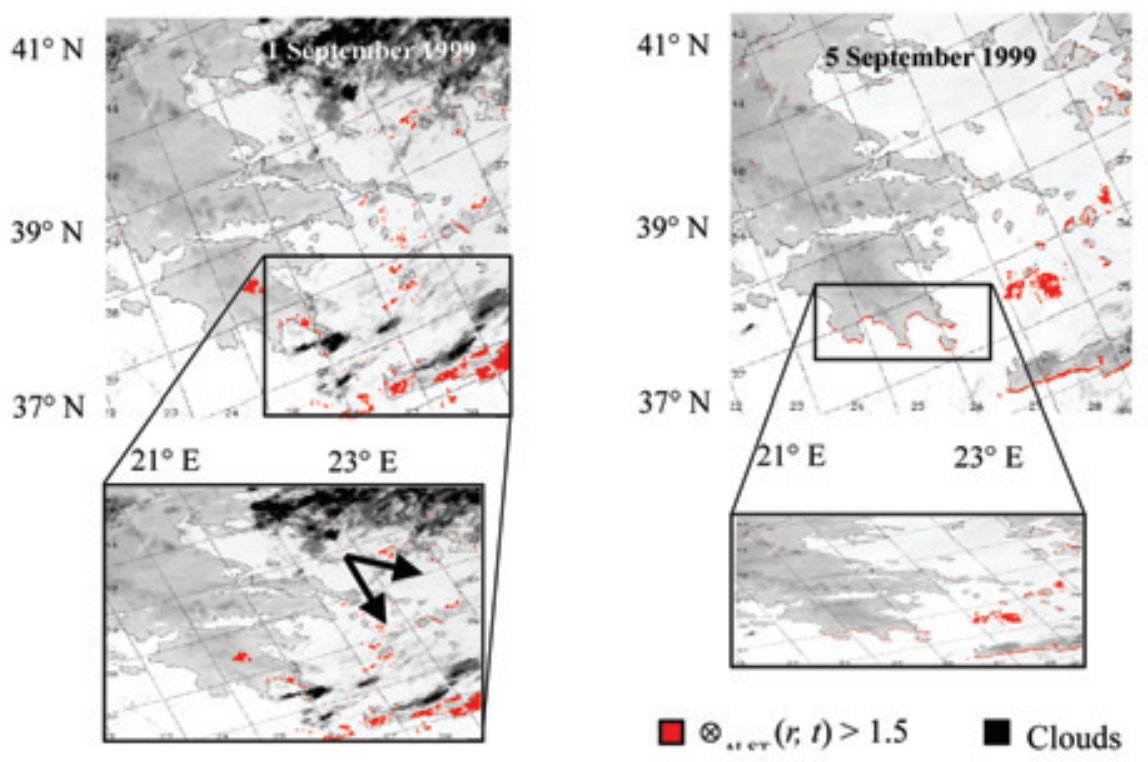

Fig. 6. Occurrence of non-persistent anomalies related to cloud passage (on the left) and navigation errors (on the right): the RST approach applied to polar satellite data (NOAA-AVHRR). Results of analysis of the daily $\otimes_{\Delta L S T}(r, t)$ index computation on the epicentral area of September 7th 1999 Athens's earthquake. The black arrows indicate the cloud system which is probably responsible for the anomalous patterns, of similar shape, affecting Crete island. In the right image, spurious effects due to wrong co-location are quite evident along Southern coasts of Peloponnesus and Crete (adapted from Filizzola et al., 2004) .

bly related to an impending earthquake, even in the case they have similar intensity (Aliano, 2004; Filizzola et al., 2004; Abbate, 2005). In this context, it is worth noting that the overestimation of cloudy pixels could also emphasize similar drawbacks. A reliable cloud-mask is then mandatory to minimize this problem. To this aim, the RST approach has also been successfully applied for cloud detection (as shown in Pietrapertosa et al., 2001; and in Cuomo et $a l ., 2004)$, in order to avoid an overestimation of cloudy pixel number across the scene.

The sporadic presence of residual anomalies which are isolated enough in space and/or so ephemeral to survive the space/time averaging processes at the bases of the RST method, should be also denounced. In fact, the RETIRA index, being based on time averaged quantities, is intrinsically not protected from such signal outliers, which turn out to be related to very local, in space and time, natural/observational conditions (examples in Filizzola et al., 2004). However, it is expected that a time-averaging process carried out on more extended time-series, increasing the frequency of appearance of the phenomena responsible for such TIR outliers, should reduce or vanish their occurrence. At the same time, the request for spatial-temporal persistence of TIR anomalies turns out particularly important to identify the ones which are more significant in the context of seismically active area monitoring.

The partial overcoming of the limits related to cloud presence is expected to be obtained by means of the use of MicroWave (MW) sensors which, by penetrating (not-raining) clouds, allow us to observe the Earth's surface in whatever weather condition. Even if passive MW sensors operate with a spatial resolution $(10-50 \mathrm{~km}$ nadir view) which is much lower than the one (1-5 km) achievable by TIR sensors, it remains largely sufficient to monitor thermal anomalies 
which we always observed at a wider scale around the epicentre zone. Passive MW sensors are presently on board polar satellite platforms only, but the presence of a MW sensor aboard a geostationary platform has already been proposed by JPL-NASA. Such a satellite package (named GeoSTAR: Geostationary Synthetic Thinned Aperture Radiometer), combining all the previously described advantages offered by MW sensors and geostationary platforms, represents at the moment the best choice for further, significant, $\mathrm{S} / \mathrm{N}$ ratio improvements (see fig. 1).

However, the use of MW sensors does not allow us to eliminate all spurious effects due to cloudiness. This is the case of the appearance of TIR anomalies which may be explained by night time cloud passages. In fact, if clouds are present, some of the heat emitted from the Earth's surface is trapped by the clouds, which are composed of water vapour (a greenhousegas) and reemitted back towards the ground, leading to an increase of the surface temperature and producing a local warming effect. Such thermal anomalies can be comparable in intensity to the ones observed in some correlation with seismic events. However, also in this case, the spatial signature and the temporal dynamics of such anomalies may allow us to identify their true origin. In fact, the shape of the thermal anomaly is similar to the shape of the cloud responsible for it (pictures on the left in fig. 6) and its time permanence is limited to the cloud life/passage.

Other spurious effects can be introduced by an uncorrected image navigation which may cause false, intense thermal anomalies where sea pixels turn out to be erroneously co-located over land portions. As a consequence, it may happen that in the computation of $\otimes_{V}(\boldsymbol{r}, t)$, the $V(\boldsymbol{r}, t)$ value of a sea pixel is compared with a reference value $\mu_{V}(\boldsymbol{r})$ of a land pixel, which is lower than the expected value for a sea pixel during the night. This way, anomalous values of the ALICE indexes are sometimes recorded along coast lines. This is not rare for polar platforms, as shown in Filizzola et al. (2004) and in fig. 6 (right side), but the use of geostationary satellite data is expected to strongly reduce such co-location/navigation errors. It should be highlighted that, even if very rarely, geostationary platforms are not completely exempted from this kind of errors. Therefore, a position of anomalous values along the sea-land boundary should make us suspicious about a possible colocation error, so that in such cases an additional check is strongly recommended.

Waiting for a GeoSTAR-like system, TIR sensors having split window capabilities onboard geostationary satellites already operating could be usefully employed. In fact the use of a RETIRA index based on the choice $V(\boldsymbol{r}, t)=$ $=\Delta \operatorname{LST}(r, t)$ will allow us to strongly reduce, in the absence of clouds, the contribution to the observational noise related to the variability of water vapour content in the atmosphere. In the case of the AVHRR sensor, this noise reduction, obtained moving from $V(\boldsymbol{r}, t)=\Delta T(\boldsymbol{r}, t)$ to $V(\boldsymbol{r}, t)=$ $=\Delta \operatorname{LST}(\boldsymbol{r}, t)$, produced an increase in $\mathrm{S} / \mathrm{N}$ ratio from 0.6 to 1.0. In the case of geostationary TIR sensors, $\mathrm{S} / \mathrm{N}$ ratios between 2 and 3.5 were achieved by using $V(\boldsymbol{r}, t)=\Delta T(\boldsymbol{r}, t)$ so that $\mathrm{S} / \mathrm{N}$ ratios between 3 and 6 could be expected by using $V(\boldsymbol{r}, t)=\Delta \operatorname{LST}(\boldsymbol{r}, t)$. At present TIR sensors with the split window capability are available onboard the following main geostationary satellites:

- GOES-8/11, but the same package is no foreseen on-board GOES-12 and on the next generation of GOES ( $\mathrm{M}$ to $\mathrm{P}$ series) satellites at least for the next 10 years.

- MetSAT satellites operated since 2005 by Japan Meteorological Agency, will become suitable for our research purposes in the next few years as soon as a longer time-serie of observations will be available.

- MSG (Meteosat Second Generation, launched by EUMETSAT in 2003) with its SEVIRI (Spinning Enhanced Visible and Infrared Imager) sensor, will soon start to guarantee time series of records (on the hemisphere containing Europe and Africa) long enough to implement RST analysis with a RETIRA index like $\otimes_{\Delta \mathrm{LST}}(\boldsymbol{r}, t)$.

\section{Conclusions}

This paper has tried to offer a first assessment of the achievements, residual limits and perspectives, related to the use of an advanced satellite 
data analysis technique (RST) to monitor earthquake active regions. The analysis has been performed on the basis of results achieved by applying different algorithms to different satellite data in the case of approximately ten earthquakes which occurred in three different continents. The new test-cases of Hector-Mine (California, October 16th 1999, $M_{s}=7.4$ ) and Kocaeli-Izmit (Turkey, August 17th 1999, $M_{s}=7.8$ ) earthquakes have been discussed, demonstrating RST performances achievable on satellite sensors (GOES), geographic areas (North America) and algorithms $(V(\boldsymbol{r}, t)=T(\boldsymbol{r}, t))$ which have never been tested before.

Even if such an analysis does not allow us to relate (or to exclude!) observed thermal anomalies definitely to impending earthquakes, which was not the purpose of this paper, it demonstrated at least: a) that a strong improvement of $\mathrm{S} / \mathrm{N}$ ratio (around the doubling) is achievable simply moving from polar to geostationary satellites; b) that significant $\mathrm{S} / \mathrm{N}$ improvements are achievable by using TIR sensors with split-window capabilities; c) the crucial role played by a space-time persistence test in order to select TIR anomalies possibly associated to impending earthquakes.

Problems still remain in interpreting thermal signals in a seismogenetic region: understanding whether or not the observed anomalous TIR signals are in statistical significant relation with time and place of incoming earthquakes or they are on the contrary related to other natural phenomena. However, the analyses performed on hundreds of satellite images allowed authors to highlight the role that TIR anomaly shape and space-time persistence analyses can play to decide whether or not they could be related to seismic activity.

On the other hand, if the presence of clouds limits the applicability of such a space-time persistence test on TIR anomalies, the use of satellite packages operating in the MW spectral region could help to overcome such limitations: the lower spatial resolution offered by passive MW sensors does not seem to be a vital requirement for such studies indeed. Major improvements are moreover expected by the combination between MW sensors and satellite geostationary attitude, which happens in GeoSTAR.
While we are waiting for the GeoSTAR satellite, geostationary satellite sensors having split window capabilities (GOES-8/11 for the past, MetSAT and MSG for next years) can already be used, which are expected to play the major role in the next few years.

\section{Acknowledgements}

The authors would like to thank Prof. Paul Menzel and Dee Wade from CIMSS-SSEC Data Centre (University of Wisconsin - Madison) for their kind support and for providing GOES data used to study the Hector Mine earthquake. This work was supported by the Italian Space Agency (Contract No. I/R/173) within the framework of «SeisMASS» (Seismic area Monitoring by Advanced Satellite System) Project and by EC and ESA through the Network of Excellence «GMOSS» (Contract No. SNE3CT-2003-503699) in the framework of GMES Program.

\section{REFERENCES}

AbBate, A. (2005): Robust TIR satellite techniques for seismically active area monitoring: performances and limits of the applicability in the case of 1997 UmbriaMarche (Italy) earthquake, Ph.D. Thesis (University of Basilicata, Potenza, Italy), (in Italian).

Aliano, C. (2004): Robust TIR satellite techniques for seismically active area monitoring: the case of 1997 Umbria-Marche (Italy) seismic sequence, Ph.D. Thesis (University of Basilicata, Potenza, Italy), (in Italian).

Aliano, C., R. Corrado, C. Filizzola, N. Pergola and V. Tramutoli (2007): Robust Satellite Techniques (RST) for seismically active areas monitoring: the case of $21 \mathrm{st}$ May, 2003 Boumerdes/Thenia (Algeria), Multitemp 2007, 18th-20th July 2007, Louven, Belgium, doi: 10.1109/MULTITEMP.2007.4293042

BArka, A.A. (1992): The North Anatolian fault zone, Ann. Tectonicae, VI, 164-195.

BECKER, F. and Z.L. Li (1990): Towards a local split window method over land surface, Inter. J. Remote Sensing, 11, 369-393.

Bonfiglio, A., M. Macchiato, N. Pergola., C. PietraperTOSA, V. TRAMUTOLI (2005): AVHRR automated detection of volcanic clouds, Inter. J. Remote Sensing, 26 (1), 9-27.

Cervone, M. Kafatos, D. Napoletani and R.P. Singh (2006): An Early warning system for coastal earthquakes, Adv. Space Res. 37, 636-642.

Corrado, R., R. Caputo, C. Filizzola, N. Pergola, C. Pietrapertosa and V. Tramutoli (2005): Seismically 
Robust TIR satellite techniques for monitoring earthquake active regions: limits, main achievements and perspectives

active areas monitoring by robust TIR satellite techniques: a sensitivity analysis on low magnitude earthquakes occurred in Greece and Turkey since 1995, Natural Haz. Earth Sys. Sci., 5, 101-108.

Cuomo, V., R. LAsaponara and V. Tramutoli (2001): Evaluation of a new satellite-based method for forest fire detection, Inter. J. Remote Sensing, 22 (9), 17991826.

Cuomo, V., C. Filizzola, N. Pergola, C. Pietrapertosa and V. Tramutoli (2004): A self-sufficient approach for GERB cloudy radiance detection, Atmos. Res., 72, (1-4), 39-56.

DeY, S. and R.P. SingH (2003): Surface latent heat flux as an earthquake precursor, Natural Haz. Earth Sys. Sci., 3, 749-755.

Di Bello, G., C. Filizzola, T. Lacava, F. Marchese, N. Pergola, C. Pietrapertosa, S. Piscitelli, I. Scaffidi, and V. Tramutoli, (2004): Robust Satellite Techniques for Volcanic and Seismic Hazards Monitoring, Ann. Geophysics, 47 (1), 49-64.

Filizzola, C., N. Pergola, C. Pietrapertosa and V. TraMUTOLI (2004): Robust satellite techniques for seismically active areas monitoring: a sensitivity analysis on September 7th 1999 Athens's earthquake, Phys. Chemistry Earth, 29, 517-527.

Filizzola, C., T. Lacava, F. Marchese, N. Pergola, I SCAFFIDI and V. TRAmUtoli (2007): Assessing RAT (Robust AVHRR Techniques) performances for volcanic ash cloud detection and monitoring in near realtime: The 2002 eruption of Mt. Etna (Italy), Remote Sensing Environ., 107 440-454.

GELLER, R.J. (1997): Earthquake prediction: a critical review, Geophys. J. Int. 131, 425-450.

Genzano, N., C. Aliano, C. Filizzola, N. Pergola and V. Tramutoli (2007): A robust satellite technique for monitoring seismically active areas: The case of BhujGujarat earthquake, Tectonophysics, 431, 197-210.

Gorny, V.I., A.G. SAlman, A.A. Tronin et al. (1988): The Earth's outgoing IR radiation as an indicator of seismic activity, Proc. Acad.Sci. USSR, 301, 67-69.

Lacava,T., V. Cuomo, E. V. Di Leo, N. Pergola, F. RoMANO and V. TRAMUTOLI (2005): Improving soil wetness variations monitoring from passive microwave satellite data: the case of April 2000 Hungary flood, Remote Sensing Environ., 96 (2), 135-148.

Lacava, T., E.V. Di Leo, N. Pergola and V. Tramutoli (2006): Space-time soil wetness variations monitoring by a multi-temporal microwave satellite records analysis, Physics Chemistry Earth, 31 1274-1283

Marchese, F., N. Pergola and L. Telesca (2006): Investigating the temporal fluctuations in satellite Advanced very High Resolution Radiometer thermal signals measured in the volcanic area of Etna (Italy), Fluctuations Noise Lett., 6 (3) 305-316.

Ouzounov, D. and F. Freund (2004): Mid-infrared emission prior to strong earthquakes analyzed by remote sensing data, Adv. Space Res., 33, 268-273.

Pergola, N., C., Pietrapertosa, T., Lacava and V. TramuTOLI (2001): Robust satellite techniques for monitoring volcanic eruptions, Ann. Geophysics, 44 (2), 167-177.

Pergola, N., V. Tramutoli and F. Marchese (2004a): Automated detection of thermal features of active volcanoes by means of infrared AVHRR records, Remote
Sensing Environ., 93, 311-327.

Pergola, N., V. Tramutoli, I. Scaffidi, T. LaCaVa and F. MARCHESE (2004b): Improving volcanic ash clouds detection by a robust satellite technique, Remote Sensing Environ., 90 (1), 1-22.

Pietrapertosa, C., N. Pergola, V. Lanorte and V. TraMUTOLI (2001): Self Adaptive Algorithms for Change Detection: OCA (the One-channel Cloud-detection Approach) an adjustable method for cloudy and clear radiances detection, in Technical Proceedings of the Eleventh International (A)TOVS Study Conference (ITSC-XI) Budapest, 20-26 September 2000, edited by J.F. LE MARShaLl and J.D. JASPER, Bureau of Meteorology Research Centre, Melbourne, 281-291.

QIANG, Z.-J. and C.-G. DiAn, (1992): Satellite thermal infrared impending temperature increase precursor of Gonghe earthquake of magnitude 7.0, Qinghai Province, Geosci., 6 (3), 297-300.

QIANG, Z.-J., X.-D. XU and C.-G. DiAn (1991): Thermal infrared anomaly precursor of impending earthquakes, in Chinese Sci. Bull., 36 (4), 319-323.

QIANG, Z.-J., X.-D. Xu and C.-G. Dian (1997): Thermal infrared anomaly precursor of impending earthquakes, in Pure Appl. Geophys., 149, 159-171.

SAlman, A., W.G. Egan and A.A. TRONIN (1992): Infrared remote sensing of seismic disturbances, in Polarization and Remote Sensing (SPIE, San Diego, CA), 208-218.

SARAF, A.K. and S. ChOudHury (2005a): Satellite detects surface thermal anomalies associated with the Algerian earthquakes of May 2003, Inter. J. Remote Sensing, 26 (13), 2705-2713.

SARAF, A.K. and S. CHOUdHURY (2005b): NOAA-AVHRR detects thermal anomaly associated with the 26 January 2001 Bhuj earthquake, Gujarat, India, Inter. J. Remote Sensing, 26 (6), 1065-1073.

Scholz, C.H., L.R. SYKeS and Y.P. AGgar (1973): Earthquake Prediction: a physical basis, Science, 181, 803810 .

Singh, R.P., S. BhoI and A.K. SAHOo (2002): Changes observed on land and ocean after Gujarat earthquake of January 26, 2001 Using IRS Data, Int'l J. Remote Sensing, 23 (16), 3123-3128.

Tramutoli, V. (1998): Robust AVHRR Techniques (RAT) for Environmental Monitoring: theory and applications, in Earth Surface Remote Sensing II, edited by G. CeCCHI and E. Zilioli, SPIE Pubbl. 3496, 101-113.

Tramutoli, V. (2005): Robust Satellite Techniques (RST) for natural and environmental hazards monitoring and mitigation: ten years of successful applications, in ISP MSRS 2005 Conference Proceedings, Beijing, China.

Tramutoli, V., G. Di Bello, N. Pergola and S. PiscitelLI, (2001a): Robust satellite techniques for remote sensing of seismically active areas, Ann. Geofis., 44 (2), 295-312

Tramutoli, V., N. Pergola and C. Pietrapertosa (2001b): Training on NOAAAVHRR of robust satellite techniques for next generation of weather satellites: an application to the study of space-time evolution of Pinatubo's stratospheric volcanic cloud over Europe, in IRS 2000: Current Problems in Atmospheric Radiation, edited by W.L. SMith and Yu.M. TIMOFEYEV, (VA' Deepak Publishing, Hampton), 36-39.

Tramutoli, V., P. Claps, M. Marella, N. Pergola, C. 
Pietrapertosa and C. Sileo (2001c): Hydrological implications of remotely-sensed thermal inertia, in $R e$ mote Sensing and Hydrology 2000, edited by M. OwE, K. Brubaker, J. Ritchie and A. Rango, vol. 267, IAHS Publ. 512, 207-211.

Tramutoli, V., V. Cuomo, C. Filizzola, N. Pergola and C. Pietrapertosa (2005): Assessing the potential of thermal infrared satellite surveys for monitoring seismically active areas: the case of Kocaeli (Izmit) earthquake, August 17, 1999, Remote Sensing Environ., 96, 409-426.

Tronin, A.A. (1996): Satellite thermal survey - A new tool for the study of seismoactive regions, Inter. J. Remote Sensing, 41 (8), 1439-1455.

Tronin, A.A. (2000): Thermal IR satellite sensor data application for earthquake research in China, Inter. J. Re- mote Sensing, 16, 3169-3177.

Tronin, A.A., M. Hayakawa and O.A. Molchanov (2002): Thermal IR satellite data application for earthquake research in Japan and China, J. Geodyn., 33 (45), 519-534.

USGS (2000): Implications for earthquake risk reduction in the United States from the Kocaeli, Turkey, Earthquake of August 17, 1999, USGS Circular 1193 (available at the web site http://pubs.usgs.gov/ circ/2000/c1193/index.html/).

Valensise, G., D. Pantosti, G. D’Addezio, F.R. Cinti, and L. CUCCI (1993): L'identificazione e la caratterizzazione di faglie sismogeniche nell'Appennino centro-meridionale e nell'arco calabro: nuovi risultati e ipotesi interpretative, in Proceedings of the GNGTS-CNR Annual Meeting, Roma, 331-342. 